CARDIOVASCULAR MEDICINE

\title{
Improving care for patients with acute coronary syndromes: initial results from the National Audit of Myocardial Infarction Project (MINAP)
}

\section{J S Birkhead, L Walker, M Pearson, C Weston, A D Cunningham, A F Rickards, on behalf of the MINAP Steering Group}

Heart 2004;90:1004-1009. doi: 10.1136/hrt.2004.034470

See end of article for authors' affiliations

\section{Correspondence to:} DrJ S Birkhead Department of Cardiology, Northampton General Hospital, Northampton NN1 1BD, UK; John. birkhead@ngh.nhs.uk

Accepted 2 April 2004
Objective: To describe the improvements in care that have followed the introduction of an electronic data entry and analysis system providing contemporary feedback on the management of acute coronary syndromes in 230 hospitals in England and Wales.

Design: Observational study

Methods: A secure electronic system was used to transfer encrypted data on patients with acute coronary syndromes from collaborating hospitals to central servers for analysis. Immediate online data entry to the central servers by hospitals allowed contemporary analyses of performance and immediate comparison with the national aggregate performance.

Results: The records of 156902 patients receiving a final diagnosis of acute coronary syndrome during three years between October 2000 and September 2003 were analysed. Of 69113 patients with ST segment elevation infarction, $75.4 \%$ received thrombolytic treatment. Between the first and last years of the study the median interval from hospital arrival to treatment fell for eligible patients from 38 (interquartile range 22-58) to 20 (interquartile range 14-28) minutes. By mid $200377.6 \%$ were receiving thrombolytic treatment within 30 minutes of arrival. The proportion treated within two hours of onset of symptoms increased from $32.5 \%$ to $40.3 \%$ (a difference of 7.8 percentage points, $p<0.0001$ ). The use of secondary prevention medication for acute coronary syndromes increased over this period: angiotensin converting enzyme inhibitors, $62.4 \%$ to $72.4 \%$; $\beta$ blockers, $76.3 \%$ to $82.6 \%$; statins, $69.6 \%$ to $83.8 \%$; and aspirin, $89.3 \%$ to $90.2 \%$.

Conclusion: The provision of contemporary online performance analyses has underpinned substantial improvement in the care of patients with acute coronary syndromes.
A number of interventions are known to improve outcome from acute myocardial infarction. ${ }^{1-4}$ The extent to which these treatments are used in clinical practice has been subject to careful examination by national and international groups, and analyses have shown considerable variation in care and potential for improvement. ${ }^{5-9}$ While surveys of national and international performance by registries depict quality of care and variation within and between countries and over time, the extent to which registries can effect immediate change in current practice is uncertain, as feedback to clinicians is inevitably delayed by analysis and distribution of results. To allow clinicians and others involved in the immediate care of patients to respond to targets or evidence based recommendations, it is necessary to provide contemporary feedback on local performance, ideally with a comparison of contemporary national or other aggregate performance. Overcoming the technical challenge of providing immediate comparative analyses of individual hospital performance has had to await the development of a reliable and secure electronic system for the transmission of data for analysis, as these data contain confidential patient and physician identifiers.

Although small improvements in care have previously been shown in limited collaborative audit in the UK, sustained countrywide analysis of the process of care and outcome has previously not been possible. ${ }^{10}{ }^{11}$ In 2000 the National Service Framework for coronary heart disease set time limited targets for the improvement of care for patients with acute myocardial infarction in England. ${ }^{12}$ These targets included the performance of the emergency ambulance service, the provision of reperfusion treatment, and the use of secondary prevention medication.

We describe the use of a national online electronic reporting and analysis system to monitor the process of care of patients with acute coronary syndromes. This is the outcome of a collaboration between the National Audit of Myocardial Infarction Project (MINAP) and the Central Cardiac Audit Database (CCAD) group. ${ }^{13} 14$ This project differs from a simple prospective registry of coronary heart disease in being designed primarily to provide hospitals with continuously updated contemporary analyses of the care of their patients. This permits collaborating hospitals, although not at present the ambulance service, to make immediate comparisons of local performance with up to date national aggregate analyses. This permanent data collection and analysis system can examine care of all aspects of acute coronary heart disease. It now covers all English hospitals caring for patients with heart attack, the majority (17 of 18) of Welsh hospitals, and some hospitals in Scotland.

We examined records of 195095 patients who were admitted with symptoms suggestive of an acute coronary syndrome between October 2000, when the project began, and September 2003 to evaluate contemporary performance in the care of infarction and to examine longitudinal trends

Abbreviations: CCAD, Central Cardiac Audit Database; $\mathrm{Cl}$, confidence interval; IQR, interquartile range; MINAP, National Audit of Myocardial Infarction Project 
in the provision of thrombolytic treatment and secondary prevention medication during this time period.

\section{METHODS}

The development of this project is described in detail elsewhere. ${ }^{13}$ The project uses a highly secure electronic data entry transmission and analysis system developed by the CCAD group to collect and analyse records of patients with all types of acute coronary syndrome. ${ }^{14}$ The database uses a dataset developed by the MINAP steering group. ${ }^{15}$ The dataset is harmonised with the datasets used by the British Cardiovascular Intervention Society and the Society of Cardiothoracic Surgeons. ${ }^{16}$ The data set has the formal approval of the English Data Standards Board and is part of the National Health Service (NHS) data dictionary. ${ }^{17}$

The system uses encryption of patient and physician identifiers to allow secure transfer of data over the internet or NHSNet between hospitals and the central servers, which are housed in two geographically separate places. Patient data can be entered either directly online or, where connection speeds are slow, into a replica of the central database (containing only the records of that hospital) that resides on a local computer. Hospitals may see their performance analyses on line and compare them with the national aggregate through the online data entry point or through a password protected web browser.

\section{Data confidentiality and patient consent}

Confidentiality of patient and physician identifiers is ensured by an encryption key unique to each contributing hospital. The project has approval from the Patient Information Advisory Group, a committee appointed by the English Secretary of State for Health under Section 60 of the English Health and Social Care Act (2001), to use patient and physician identifiable information essential to the project, specifically the unique national health service number, without individual patient consent. ${ }^{18}$

\section{Data completeness and validation}

Completeness of individual records is checked on line by examining the completion of 11 mandatory fields from each record of patients with a diagnosis of ST elevation infarction. Hospitals receive an individual completeness rating. Completeness ratings greater than $90 \%$ are achieved by most hospitals. An online data validation tool has now been pilot tested and use will become mandatory in 2004.

\section{Data entry}

Hospitals are encouraged to enter data directly on to the central servers at the time of care for the patient. Once a patient record is initiated changes and additions can be made at any time. The identity of the person entering the data and the date and time of the new entry are recorded centrally.

\section{Data analysis}

Analyses were based on records entered into the MINAP database during three years from October 2000 to September 2003. Data were analysed in either six month or 12 month periods starting from October 2000. Comparisons of categorical data between time periods were expressed as percentages and the differences given with the 95\% confidence interval (CI). Time intervals were expressed as the median and interquartile range (IQR). Time intervals were compared by dichotomising the data and using a $t$ test for independent samples.

The number of hospitals collaborating in the project increased throughout the period of study. At the end of the first six months of the project, 96 hospitals were returning records. By March 2003, 230 of 231 acute care hospitals in England and Wales were returning records.

\section{RESULTS}

During three years records were returned on 195095 patients admitted to 230 English and Welsh hospitals with symptoms suggestive of an acute coronary syndrome. Analyses were based on 156902 patients given a discharge diagnosis of an acute coronary syndrome, of whom 69113 had cardiographic evidence of ST segment elevation infarction (fig 1). The discharge diagnosis was that recorded by the returning hospital according to locally agreed biochemical diagnostic criteria. The mean (SD) age of patients with ST elevation infarction was 67.8 (13) years and for other acute coronary syndromes it was 70.3 (13) years. Men constituted $64.4 \%$ of the population. For 53208 patients a diagnosis of ST elevation infarction was based on the appearances of the admission electrocardiograph. Of these, 44413 (83.5\%) received thrombolytic treatment and 8795 (16.5\%) did not receive this treatment. Of all patients with ST elevation infarction, $52105(75.4 \%)$ had thrombolytic treatment and $401(0.6 \%)$ had primary coronary angioplasty.

\section{Reaching hospital}

The time taken for patients with ST elevation infarction to respond to the onset of symptoms increased from the first year to the third year from a median of 75 (IQR 30-210) to 80 (30-225) minutes. Of 7111 patients who had a final diagnosis of ST elevation infarction in the first year, $2059(29 \%)$ called for help less than 30 minutes after onset of symptoms. In the third year 5205 of $19500(26.7 \%)$ called for help in less than 30 minutes (for a difference of -2.3 percentage points, $95 \%$ $\mathrm{CI}-1.0$ to $-3.5, \mathrm{p}<0.0001)$.

Of 156902 patients with a final diagnosis of acute coronary syndrome there were data recording how 126251 $(80.5 \%)$ reached hospital. Of these, 106498 (84.4\%) came by emergency ambulance after either a call to a doctor or a call direct to the emergency service. Although there was a shift away from calling a doctor for advice towards greater use of the emergency service, there was also an increase in self referral to hospital (table 1). However, despite these shifts in behaviour, there was no change in the numbers of patients who reached hospital within 30 minutes of a call for help. Of 14455 coming to hospital by ambulance in the first year, $2859(19.8 \%)$ reached hospital in under 30 minutes from a call for help and in the third year, when 43179 came to hospital by ambulance, 8346 (19.3\%) arrived within 30 minutes. The median delay from a call for help to arrival was unchanged: in the first year it was 45 (IQR 34-64) minutes and in the third year, 43 (IQR 34-57) minutes.

\section{Performance in hospital}

The number of eligible patients receiving thrombolytic treatment within 30 minutes of arrival in hospital increased rapidly over three years (fig 2). An eligible patient was defined as having ST segment elevation infarction on the admission electrocardiograph, without a contraindication to thrombolytic treatment. In addition, treatment was not delayed due to factors such as uncontrolled hypertension or initial refusal to consent to treatment. Of 2038 eligible patients, $868(42.6 \%)$ received thrombolytic treatment within 30 minutes of arrival in hospital in the first six months. In the final six months this had increased to 5394 of 6953 eligible patients $(77.6 \%$ ) (difference 35 percentage points, 95\% CI $32.6 \%$ to $37.3 \%, \mathrm{p}<0.0001)$. Between the first and last six months there was a fall in the median delay between arrival in hospital and treatment from 38 (IQR 22-58) to 20 (IQR 14-28) minutes. 


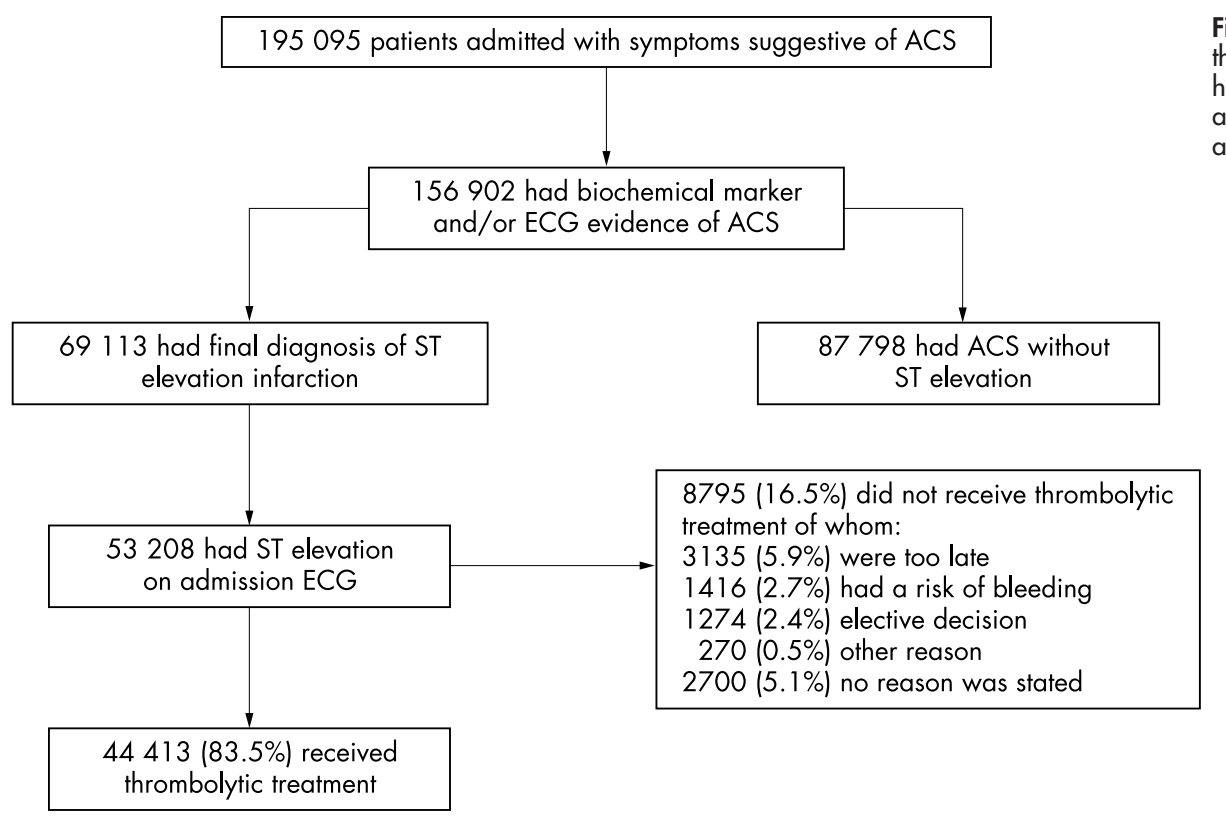

Figure 1 Study population and use of thrombolytic treatment for patients who had ST segment elevation on the admission electrocardiograph. ACS, acute coronary syndrome.

Thrombolytic treatment increasingly was given to eligible patients in emergency departments. Treatment rate rose from $56.5 \%$ to $72.7 \%$ of eligible patients between the first and final six months of the study. Fewer patients were treated in the cardiac care unit after an initial assessment in the emergency department, and there was a small fall in the use of direct admission to the cardiac care unit (table 2). At the same time emergency department clinicians became increasingly involved in the care of patients with infarction and general medical teams became less involved (table 3 ).

\section{Changes from onset of symptoms to treatment}

Of 1523 patients eligible for immediate thrombolytic treatment in the first six months, 303 (19.9\%) were treated within 60 minutes of calling for help. In the last six months of the study treatment had increased to 2537 of 5438 patients (46.7\%) (difference 26.8 percentage points, 95\% CI 24.4 to $29.2, \mathrm{p}<0.0001)$. Of 6363 eligible patients given thrombolytic treatment during the first six months, 2068 (32.5\%) were treated within two hours of onset of symptoms and $3481(54.7 \%)$ within three hours. In the last six months, 14189 eligible patients had thrombolytic treatment, of whom $5720(40.3 \%)$ were treated within two hours and 8735 (61.6\%) within three hours (difference at two hours 7.8 percentage points, $95 \%$ CI 6.4 to $9.2, \mathrm{p}<0.0001$; difference at three hours 6.9 percentage points, $95 \%$ CI 5.4 to 8.3 , $\mathrm{p}<0.0001)$.

\section{Use of secondary prevention medication}

The use of $\beta$ adrenergic blockers, statins, angiotensin converting enzyme inhibitors, and aspirin was examined for all patients with a final diagnosis of acute coronary syndrome. The use of $\beta$ blockers, statins, and angiotensin converting enzyme inhibitors increased and use of aspirin was unchanged at around $90 \%$ (table 4). Patients who were not receiving a drug because of a stated contraindication were excluded from analysis.

\section{DISCUSSION}

These analyses are derived from records entered over three years between October 2000, when recruitment began, and the end of September 2003. By the middle of 2003, records were being contributed by 230 of 231 English and Welsh hospitals; these analyses therefore closely reflect national performance in the care of infarction.

Changes in performance before admission to hospital The fall in numbers of patients seeking help within 30 minutes of onset of symptoms, from $29 \%$ to $26.7 \%$ between the first and last six months, was a continuation of a trend seen over the past decade. In 1993 the proportion calling for help within 30 minutes was $43.5 \%$ and in 1997 it was $37 \%{ }^{11}$ In 1997 Blohm and colleagues ${ }^{19}$ found no evidence that educational initiatives to shorten patient delay had any lasting benefit, and it is clear from present evidence that

\begin{tabular}{|lllll}
\hline \multicolumn{4}{|l|}{ Table 1} & Changes in patient response to symptoms over three years \\
\hline Year & Called doctor & $\begin{array}{l}\text { Called emergency } \\
\text { service }\end{array}$ & $\begin{array}{l}\text { Made own way } \\
\text { to hospital }\end{array}$ & Total \\
\hline $2000-1$ & $4538(23 \%)$ & $12404(62.9 \%)$ & $2779(14.1 \%)$ & 19721 \\
$2001-2$ & $8811(18.7 \%)$ & $31166(66.4 \%)$ & $6927(14.8 \%)$ & 46904 \\
$2002-3$ & $9623(16.2 \%)$ & $39956(67 \%)$ & $10047(16.9 \%)$ & 59626 \\
$\begin{array}{l}\text { Difference (percentage } \\
\text { points) }\end{array}$ & -6.9 & 4.1 & 2.8 & \\
$95 \%$ Cl 2000-1 and & -6.2 to -7.5 & 3.3 to 4.9 & 2.2 to 3.3 & \\
$2002-3$ & & & \\
\hline
\end{tabular}




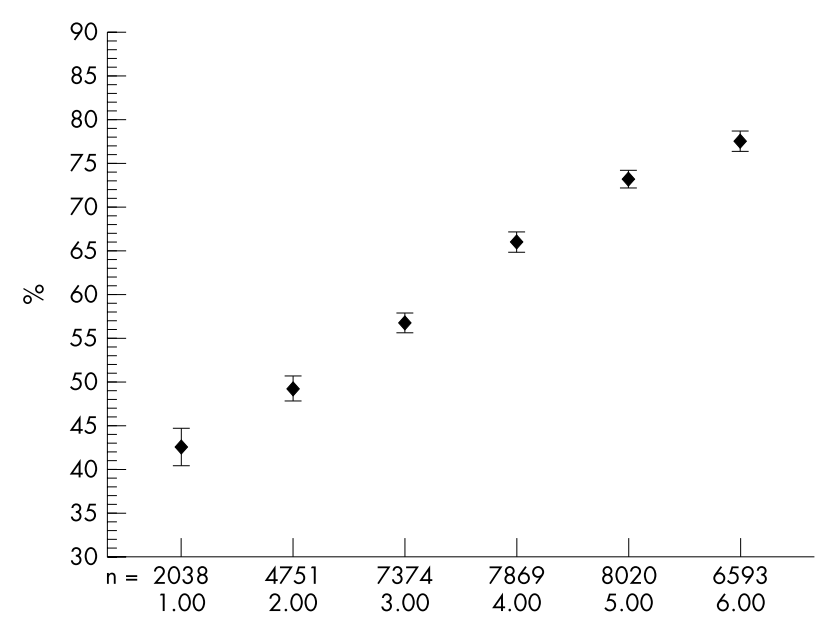

Figure 2 Proportion (with 95\% confidence intervals) of eligible patients given thrombolytic treatment in less than 30 minutes from arrival in hospital. Six month periods are numbered $1-6$ beginning in October 2000. Number given treatment in each six month period is shown on the $x$ axis; total number $37005 . p<0.0001$ for sequential comparisons between each six month interval.

there has been no subsequent improvement. The reasons for this increasing delay are not clear but increasing age, known to delay presentation, may be relevant. The mean age of patients with ST elevation infarction described here was 67.8 years compared with 64.1 years in 1993 and 65.7 years in $1997 . .^{1120}$

No reduction in delay from a call for help to arrival in hospital was seen. Less than $20 \%$ patients reached hospital within 30 minutes of a call for help. Meanwhile the median interval from a call for help to reaching hospital was 43 minutes in 2003, suggesting that there is a potential role for prehospital thrombolytic treatment for many patients. It may be unrealistic to expect significant reductions in ambulance journey times, but adopting process improvements such as prehospital treatment or even recording a good quality 12 lead ECG en route to hospital may be useful. At present only 12 of $31(39 \%)$ regional ambulance services provide prehospital thrombolytic treatment and in 2003 only about 350 patients were treated in this way. ${ }^{21}$ The potential benefit from widespread increases in the use of prehospital treatment, while of proven value for longer journey times, remains to be determined for a more urban and semirural population where journey times are short. ${ }^{22}$

\section{Performance within hospital}

In contrast to care before admission, there was a striking improvement in the process of care of patients admitted to hospital with ST elevation myocardial infarction. The median delay from arrival in hospital to thrombolytic treatment fell from 38 to 20 minutes, with $77.6 \%$ of eligible patients receiving thrombolytic treatment within 30 minutes of arrival compared with $42.6 \%$ in the first six months of the study. These improvements have come about as a result of extensive organisational change within hospitals. In particular, there was a shift of care to the point of entry to the hospital and improved triage of patients presenting with chest pain to emergency departments. There was substantially greater involvement of emergency clinicians in providing thrombolytic treatment that was previously provided by on-call medical teams. Although prescription of thrombolytic treatment by specialist nurses has been shown to be effective in reducing treatment delays, there was only a small increase in the number of patients who received their treatment in this way. The overall use of thrombolytic treatment for $75.4 \%$ of episodes of ST segment elevation infarction, both in patients presenting with ST elevation and in patients who developed ST elevation changes after admission, is higher than has been recorded elsewhere. ${ }^{23}$

\section{Improvement in overall delay}

The number of eligible patients receiving early thrombolytic treatment increased significantly. In 2003, treatment was given to $40.3 \%$ within two hours and to $61.6 \%$ within three hours. An assessment of the evidence for the relative benefits of primary angioplasty and thrombolytic treatment favours thrombolytic treatment when this can be given less than two hours from onset, while angioplasty offers greater benefit for those presenting for treatment later than two to three hours. ${ }^{24}$ On this evidence at least $40 \%$ of patients presenting with ST elevation infarction in 2003 received the optimum reperfusion strategy.

\section{Use of secondary prevention medication}

The use of secondary prevention medication at discharge for all patients with acute coronary syndromes has increased rapidly and exceeds the targets set in the English National Service Framework for coronary heart disease for patients with myocardial infarction. ${ }^{12}$ The use of aspirin, $90 \%$, is similar to that recorded elsewhere. ${ }^{26}$ Use of angiotensin converting enzyme inhibitors increased from $62.4 \%$ to $72.4 \%$, $\beta$ blockers from $76.3 \%$ to $82.6 \%$, and statins from $69.6 \%$ to $83.8 \%$. Use of these agents is greater than that previously described in other countries, although contemporary comparisons are not available. ${ }^{8627}$

\section{Comment}

These rapid improvements in hospital care have occurred against a background of targets set by the English National Service Framework for coronary heart disease. ${ }^{12}$ While awareness of centrally set targets will have motivated

\begin{tabular}{|c|c|c|c|c|c|}
\hline & \multicolumn{4}{|c|}{ Where was treatment given } & \multirow[b]{2}{*}{ Total } \\
\hline & $\begin{array}{l}\text { Emergency } \\
\text { department }\end{array}$ & $\begin{array}{l}\text { CCU direct } \\
\text { admission }\end{array}$ & $\begin{array}{l}\text { CCU (from } \\
\text { emergency } \\
\text { department) }\end{array}$ & $\begin{array}{l}\text { Elsewhere in } \\
\text { hospital }\end{array}$ & \\
\hline 2000-1 & $3838(56.5 \%)$ & $1300(19.1 \%)$ & $1438(21.2 \%)$ & $222(3.3 \%)$ & 6798 \\
\hline $2001-2$ & 9986 (65.8\%) & $2482(16.4 \%)$ & $2167(14.3 \%)$ & 539 (3.6\%) & 15174 \\
\hline $2002-3$ & $10737(72.7 \%)$ & $2398(16.2 \%)$ & $1179(8.0 \%)$ & $460(3.1 \%)$ & 14774 \\
\hline $\begin{array}{l}\text { Difference (percentage } \\
\text { points) }\end{array}$ & 16.2 & -2.9 & -13.2 & -0.2 & \\
\hline $\begin{array}{l}95 \% \mathrm{Cl} 2000-1 \text { and } \\
2002-3\end{array}$ & 14.8 to 17.6 & -1.8 to -4.0 & -12.1 to -14.2 & -0.4 to 0.7 & \\
\hline
\end{tabular}

Data were available for analysis of 36746 patients.

CCU, coronary care unit. 
Table 3 Prescriber of thrombolytic treatment to patients immediately eligible for treatment

\begin{tabular}{llllll}
\hline & \multicolumn{2}{l}{ Who gave thrombolytic treatment } & & \\
\cline { 2 - 5 } & Specialist nurse & Emergency clinician & Medical team & Cardiologist & Total \\
\hline $2000-1$ & $457(7.4 \%)$ & $2037(33 \%)$ & $3266(52.9 \%)$ & $410(6.6 \%)$ & 6170 \\
$2001-2$ & $1049(7.4 \%)$ & $6094(43 \%)$ & $6067(42.8 \%)$ & $970(6.8 \%)$ & 14180 \\
$2002-3$ & $1350(9.5 \%)$ & $7152(50.2 \%)$ & $4841(34 \%)$ & $909(6.4 \%)$ & 14252 \\
$\begin{array}{l}\text { Difference } \\
\text { (percentage points) }\end{array}$ & 2.1 & 17.2 & -19 & -0.2 & \\
$95 \%$ Cl 2000-1 and & 1.3 to 2.9 & 15.7 to 18.6 & -17.5 to -20.4 & -0.4 to 1.0 & \\
$2002-3$ & & & & & \\
\hline
\end{tabular}

Data were available for analysis for 34603 patients.

Table 4 Use of secondary prevention medication for patients with a final diagnosis of acute coronary syndrome

\begin{tabular}{lllll}
\hline & ACEI & $\boldsymbol{\beta}$ Blocker & Statin & Aspirin \\
\hline $2000-1$ & $12336 / 19757$ & $13568 / 17782$ & $13678 / 196432$ & $18722 / 20954$ \\
& $(62.4 \%)$ & $(76.3 \%)$ & $(69.6 \%)$ & $(89.3 \%)$ \\
$2001-2$ & $34215 / 49007$ & $33745 / 41744$ & $38802 / 49486$ & $46037 / 50793$ \\
& $(69.8 \%)$ & $(80.8 \%)$ & $(78.4 \% 0$ & $(90.6 \%)$ \\
$2002-3$ & $44507 / 61472$ & $42401 / 51353$ & $52078 / 62164$ & $56695 / 62876$ \\
& $(72.4 \%)$ & $(82.6 \%)$ & $(83.8 \%)$ & $(90.2 \%)$ \\
$\begin{array}{l}\text { Difference (percentage } \\
\text { points) }\end{array}$ & 10 & 6.3 & 14.2 & 0.9 \\
$95 \%$ Cl 2000-1 and & 9.2 to 10.7, & 5.6 to 7.0, & 13.4 to 14.8, & 0.3 to 1.3. \\
$2002-3$ & $\mathrm{p}<0.0001$ & $\mathrm{p}<0.0001$ & $\mathrm{p}<0.0001$ & $\mathrm{p}<0.001$ \\
\hline \multicolumn{2}{l}{ ACEl, angiotensin converting enzyme inhibitor. } \\
\end{tabular}

improvement, we believe that immediate access by hospitals to their own contemporary analyses and the ability to make immediate comparisons with national aggregate analyses has had a strong impact on performance. It is impossible to determine the relative contribution of the effects of central targets and the analysis and feedback facilities provided by MINAP; both are important to the end result.

Rapid change in performance at the rate witnessed up to the present cannot be maintained indefinitely, but the contemporary data analyses provided on line by MINAP also act as an early warning system when standards slip and can ensure that good performance is maintained. Clinical and nursing staff change frequently, and performance can potentially fall quickly if it is not constantly reviewed. Entering contemporary data during the episode of care is essential in providing up to date analyses of hospital performance and allows the system to give immediate warning of deterioration in performance. The potential for using formal statistical process control techniques for time dependent functions such as the door to needle time is being explored.

Although the primary purpose of MINAP is to provide contemporary analyses of performance to clinicians, the analyses (in differing formats) are also used by administrators of regional groups of hospitals (strategic health authorities) and the English Department of Health. The general public also receives a web based annual report in which hospitals are given a three point rating based on performance. To achieve complete national coverage it was essential to gain the trust and support of colleagues in hospitals on issues such as security and confidentiality of records and the uses to which the analyses may be put. The analyses presented here are evidence that this system has proved its worth both as an audit tool that has the confidence of clinicians and as a means for performance management for administrators.

Links with other cardiac domains, including surgery, interventional cardiology, and cardiac electrophysiology, are being developed through the unique National Health Service number to link episodes of care occurring in different places and at different times. In addition mortality tracking based on data from the National Office of Statistics is already available and vital status of patients is provided for hospitals. Thus, the analyses presented here give some indication of the potential value of a prospective and complete registry of national performance for all aspects of care of acute coronary syndromes and as the basis of a national electronic patient record for coronary heart disease.

\section{ACKNOWLEDGEMENTS}

MINAP was supported in the early stages by the Royal College of Physicians of London, and from 2000 to 2003 by the National Institute for Clinical Excellence. Subsequent funding has been provided by the Commission for Health Improvement.

\section{Authors' affiliations}

J S Birkhead, L Walker, M Pearson, Clinical Effectiveness and Evaluation Unit, Royal College of Physicians, London, UK

C Weston, Singleton Hospital, Swansea, UK

A F Rickards*, Central Cardiac Audit Database, Royal Brompton Hospital, London, UK

A D Cunningham, Central Cardiac Audit Database, Bridge of Weir, UK * Dr Rickards died on 28 May 2004

\section{REFERENCES}

1 ISIS-2 Collaborative Group. Randomised trial of intravenous streptokinase oral aspirin, both or neither among 17187 cases of suspected myocardial infarction: ISIS-2. ISIS-2 (second international study of infarct survival) collaborative group. Lancet 1988;ii:349-60.

24 Investigators. Randomised trial of cholesterol lowering in 4444 patients with coronary heart disease: the Scandinavian simvastatin survival study (4S). Lancet 1994;344:1383-9.

3 AIRE Study Investigators. Effect of ramipril on mortality and morbidity of survivors of acute myocardial infarction with clinical evidence of heart failure. The acute infarction ramipril efficacy (AIRE) study investigators. Lancet 1993;342:821-8.

4 ISIS-1 Collaborative Group. Randomised trial of intravenous atenolol among 16027 cases of suspected acute myocardial infarction: ISIS-1. ISIS-1 (first 
international study of infarct survival) collaborative group. Lancet 1986;ii:57-66.

5 GRACE Investigators. GRACE (global registry of acute coronary events): a multinational registry of patients hospitalized with acute coronary syndromes. The GRACE investigators. Am Heart J 2001;141:190-9.

6 Collinson J, Flather M, Fox KA, et al. Clinical outcomes, risk stratification and practice patterns of unstable angina and myocardial infarction without ST elevation: prospective registry of acute ischaemic syndromes in the UK (PRAIS UK). Eur Heart J 2000;21:1450-7.

7 Rogers WJ, Canto JG, Lambrew CT, et al. Temporal trends in the treatment of over 1.5 million patients with myocardial infarction in the US from 1990 through 1999. J Am Coll Cardiol 2000;36:2056-63.

8 EUROASPIRE II Investigators. Lifestyle and risk factor management and use of drug therapies in coronary patients from 15 countries. Principal results from EUROASPIRE II Euro heart survey programme. Eur Heart I 2001 ;22:554-72.

9 Fox KM, Goodman SG, Anderson FA, et al. From guidelines to clinical practice: the impact of hospital and geographical characteristics on temporal trends in the management of acute coronary syndromes. The global registry of acute coronary events (GRACE). Eur Heart J 2003;24:1414-24.

10 Birkhead JS, on behalf of the Myocardial Infarction Audit Group. Thrombolytic treatment for myocardial infarction: an examination of practice in 39 United Kingdom hospitals. Heart 1997;78:28-33.

11 Birkhead JS, on behalf of the Myocardial Infarction Audit Group. Trends in the provision of thrombolytic treatment between 1993 and 1997. Heart 1999:82:432-7.

12 Department of Health. National service framework for coronary heart disease. London: Department of Health, 2000.

13 Birkhead JS, Pearson M, Norris RM, et al. The national audit of myocardial infarction: a new development in the audit process. J Clin Excell 2002;4:379-85.

14 Rickards A, Cunningham D. From quantity to quality: the central cardiac audit database project. Heart 2000;82:18-22.

15 Royal College of Physicians. CEEU: Project: Myocardial infarction national audit project (MINAP). www.rcplondon.ac.uk/college/ceeu/ ceev_ami_home.htm (accessed 3 Jan 2004).
16 Central Cardiac Audit Database. www. ccad org.uk (accessed 3 Jan 2004).

17 Anon. NHS Information Authority NHS data dictionary and manual, version 1.3. Birmingham: NHSIA, 2002.

18 Section 60 of the Health and Social Care Act 2001 and the Patient Information Advisory Group (PIAG). www.doh.gov.uk/ipu/confiden/indexl.htm (accessed 3 Jan 2004).

19 Blohm MB, Hartford M, Karlson BW, et al. An evaluation of the results of media and educational campaigns designed to shorten the time taken by patients with acute myocardial infarction to decide to go to hospital. Heart 1996:76:430-4.

20 Gurwitz JH, McLaughlin TJ, Willison DJ, et al. Delayed hospital presentation in patients who have had acute myocardial infarction. Ann Intern Med 1997; 126:593-9.

21 Cooke M. Thrombolysis update. Candour 2003;Dec:2. www.asancep.org.uk/candour30.pdf (accessed 12 Jan 2004)

22 Pedley DK, Bissett K, Connolly EM, et al. Prospective observational cohort study of time saved by prehospital thrombolysis for ST elevation myocardial infarction delivered by paramedics. BMJ 2003;32:722-6.

23 Eagle KA, Goodman SG, Avezum A, et al, for the GRACE Investigators. Practice variation and missed opportunities for reperfusion in ST-segmentelevation myocardial infarction: findings from the global registry of acute coronary events (GRACE). Lancet 2002;359:373-7.

24 Steg PG, Bonnefoy E, Chabaud S, et al. Impact of time to treatment on mortality after prehospital thrombolysis or primary angioplasty. Circulation 2003; 108:2851-6

25 Widimsky P, Budesinsky T, Vorac D, et al. Long distance transport for primary angioplasty vs immediate thrombolysis in acute myocardial infarction: final results of the randomised national multicentre trial-PRAGUE-2. Eur Heart $J$ 2003:24:94-104.

26 Fox KAA, Goodman SG, Klein W, et al. Management of acute coronary syndromes: variations in practice and outcome. Eur Heart $J$ 2002;23: 1177-89.

27 Andersen HR, Nielsen T, Rasmussen K, et al. A comparison of coronary angioplasty with fibrinolytic therapy in acute myocardial infarction. N Engl J Med 2003;349:733-42.

\section{IMAGES IN CARDIOLOGY}

\section{Post-traumatic focal true left ventricular aneurysm} resulting in multiple bilateral rib fractures, bilateral pneumothorax, rupture of the spleen and liver, and fracture of a femur. Splenectomy, raphy of the liver, bilateral thoracic drainage, and osteosynthesis of the femur were performed. Although recovery was uneventful he kept complaining of daily thoracic pain. His ECG at rest displayed a normal sinus rhythm. Radiography of the chest revealed focal bulging of the left midventricular border (panel A, arrow). Ventriculography demonstrated a left ventricular aneurysm of the mid anterior wall (panel B, arrow). Coronary arteries remained angiographically normal. Demonstration of myocardial lining of the aneurysm by magnetic resonance imaging proved it to be a true aneurysm (panel C, arrows indicate myocardial thinning and delayed hyperenhancement).

Post-traumatic cardiac aneurysms are rare. A temporary coronary obstruction has been suggested as a potential
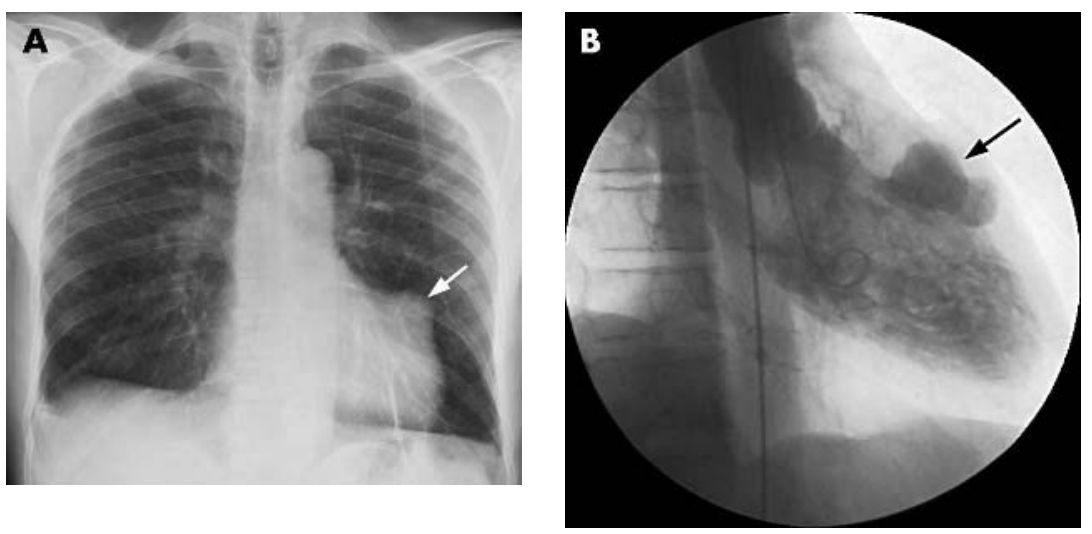

mechanism. True ventricular aneurysms have been treated surgically as well as medically. However, prospective randomised studies comparing these treatments are lacking. The patient has been treated medically for two years and his outcome has remained uneventful.
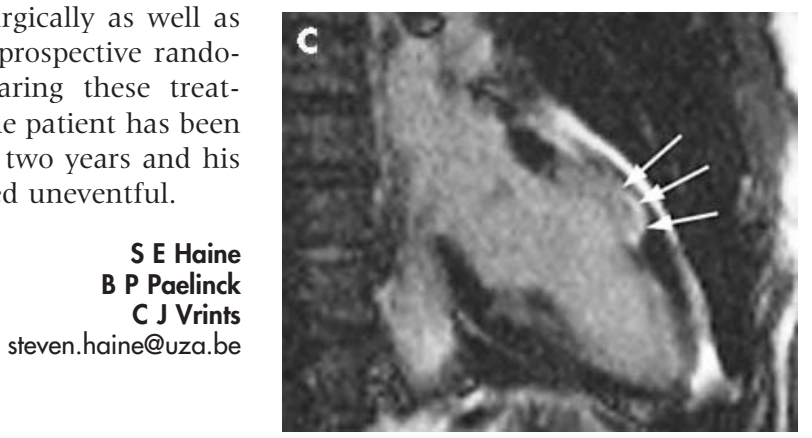